\title{
Screening tools for early neuropsychological impairment after aneurysmal subarachnoid hemorrhage
}

\author{
Ilari M. Rautalin ${ }^{1,2}$ (D) Martina Sebök ${ }^{1} \cdot$ Menno R. Germans ${ }^{1} \cdot$ Miikka Korja $^{2} \cdot$ Noemi Dannecker $^{3}$. \\ Olivia Zindel-Geisseler ${ }^{3} \cdot$ Peter Brugger $^{3} \cdot$ Luca Regli $^{1} \cdot$ Martin N. Stienen $^{1}$
}

Received: 18 June 2019 / Accepted: 14 November 2019 / Published online: 4 December 2019

(C) The Author(s) 2019

\begin{abstract}
Background Although most aneurysmal subarachnoid hemorrhage (aSAH) patients suffer from neuropsychological disabilities, outcome estimation is commonly based only on functional disability scales such as the modified Rankin Scale (mRS). Moreover, early neuropsychological screening tools are not used routinely.

Objective To study whether two simple neuropsychological screening tools identify neuropsychological deficits (NPDs), among aSAH patients categorized with favorable outcome (mRS 0-2) at discharge.

Methods We reviewed 170 consecutive aSAH patients that were registered in a prospective institutional database. We included all patients graded by the $\mathrm{mRS}$ at discharge, and who had additionally been evaluated by a neuropsychologist and/or occupational therapist using the Montreal Cognitive Assessment (MoCA) and/or Rapid Evaluation of Cognitive Function (ERFC). The proportion of patients with scores indicative of NPDs in each test were reported, and spearman correlation tests calculated the coefficients between the both neuropsychological test results and the mRS.

Results Of the 42 patients $(24.7 \%)$ that were evaluated by at least one neuropsychological test, $34(81.0 \%)$ were rated $\mathrm{mRS} 0-2$ at discharge. Among these 34 patients, NPDs were identified in 14 (53.9\%) according to the MoCA and 8 (66.7\%) according to the ERFC. The mRS score was not correlated with the performance in the MoCA or ERFC.

Conclusion The two screening tools implemented here frequently identified NPDs among aSAH patients that were categorized with favorable outcome according to the mRS. Our results suggest that MoCA or ERFC could be used to screen early NPDs in favorable outcome patients, who in turn might benefit from early neuropsychological rehabilitation.
\end{abstract}

Keywords Aneurysmal subarachnoid hemorrhage - Functional outcome - Impairment · Modified Rankin scale · Multi-dimensional outcome assessment $\cdot$ Neuropsychological outcome

\section{Introduction}

Aneurysmal subarachnoid hemorrhage (aSAH) is a lifethreatening disease with short- and mid-term mortality of roughly $40 \%$ [1]. In recent years, survival rates have increased

Ilari M. Rautalin

ilari.rautalin@helsinki.fi

1 Department of Neurosurgery, University Hospital Zurich \& Clinical Neuroscience Center University of Zurich, Zurich, Switzerland

2 Department of Neurosurgery, University of Helsinki and Helsinki University Hospital, Helsinki, Finland

3 Neuropsychology Unit, Department of Neurology, University Hospital Zurich \& Clinical Neuroscience Center, University of Zurich, Zurich, Switzerland due to improvements in risk factor control, early diagnosis, and critical care management, as well as in surgical and endovascular prevention of re-bleeding [2]. While the number of aSAH survivors is slowly rising, the assessment of patients with non-fatal outcomes is becoming increasingly relevant [3].

During the hospital period following aSAH, the outcome of survivors is often evaluated only by functional grading scales such as the modified Ranking Scale (mRS) [4] or Glasgow Outcome Scale (GOS) [5]. Despite their advantages in terms of standardizing the outcome assessment, some criticism has been raised regarding their insensitivity to neuropsychological deficits (NPDs) [6-8]. In fact, NPDs are the most common form of disabilities after aSAH; nearly half of the independent patients suffer from these impairments, causing difficulties in activities of daily living (ADLs) and return to premorbid work [9-11]. It has been shown that early initiation of appropriate 
rehabilitation after aSAH can decrease the rates of disabilities $[12,13]$. Nevertheless, early-phase screening tools that include the neuropsychological and psycho-social aspects of patient outcome are rarely conducted in neurosurgical practice or clinical trials [14].

In a recent study, Haug Nordenmark et al. [15] concluded that the majority of early NPDs after aSAH are missed by the $\mathrm{mRS}$, hence additional assessments should be included in neurosurgical practice. We aimed to determine whether two practical screening tools for NPDs can identify early neuropsychological impairments, even among aSAH patients categorized with favorable outcome that might be discharged instead of receiving inpatient rehabilitation. If a screening tool detected NPDs - even in favorable outcome patients - it could be considered for implementation in a routine discharge assessment. Diagnosing NPDs would enable initiating appropriate therapy, thereby decreasing long-term morbidity of aSAH.

\section{Material and methods}

\section{Patients}

We screened a total of 170 consecutive aSAH patients that were treated at our neurosurgical department, and discharged between January 2015 and April 2018. aSAH diagnosis was confirmed with clinical and radiological examinations (computed tomography angiography (CT-A), digital subtraction angiography (DSA), magnetic resonance angiography (MRA) and/or spinal tap). In order to be included in the study, patients had to be evaluated by the mRS and at least one additional neuropsychological test before the first hospital discharge after aSAH. Neuropsychological screenings were performed after patients had reached a stable condition (e.g. no signs of hydrocephalus, no delayed cerebral ischemia (DCI), no sodium electrolyte disorder), usually in the last days prior to the hospital discharge.

Information about patients' age, sex, hypertension (yes/no) and smoking (yes/no) was collected prospectively on admission. Information on complications, particularly hydrocephalus, cerebral vasospasm (CVS), DCI and disability outcome (mRS) were extracted from the institutional patient registry [16] or added by their retrospective chart review as needed. Case-severity of aSAH was defined by the World Federation of Neurosurgical Societies (WFNS) grading scale [17] and the amount of cisternal hemorrhage (Barrow Neurological Institute (BNI) scale [18]). In addition, treatment modality (microsurgical (clipping) vs. endovascular (coiling)) was recorded.

Patients were excluded if they had missing relevant data or documented NPDs before aSAH. In addition, those with fatal, traumatic, non-aneurysmal and perimesencephalic SAH were also excluded.

\section{Outcome assessments}

Based on previous literature [14, 19, 20], the analysis focused on NPDs; the mRS, which is currently used as the "gold standard" for disability after a stroke, was used as a reference variable [21]. The $\mathrm{mRS}$ and Montreal Cognitive Assessment (MoCA) are both recommended by the National Institute of Health (NIH) and National Institute of Neurological Disorders and Stroke (NINDS) as valid outcome measures after aSAH (common data elements (CDE) working group on unruptured cerebral aneurysms and $\mathrm{SAH}$ [22]). All assessments were made when the patients were first hospitalized after aSAH.

At hospital discharge, all patients were graded according to the $\mathrm{mRS}$ by resident and faculty neurosurgeons that had been trained and certified in its use [23]. Since fatal aSAH cases were excluded, the mRS was used to classify patients into one of six categories: 0) no symptoms, 1) no significant disabilities, 2) slight disabilities, 3) moderate disabilities, 4) moderately severe disabilities, or 5) severe disabilities. In line with the definition of the ISAT trial, favorable outcome was defined as mRS categories of 0,1 and 2 [24].

The MoCA-based evaluations were performed by neuropsychologists trained in its use, following the standard operating procedures for test conduction and scoring [25]. The MoCA is a well-studied, single-page screening tool for NPDs after aSAH that takes around $10-20 \mathrm{~min}$ to perform and uses a point-based system to evaluate patients' abilities of executive functions, naming, attention, recall, abstraction and orientation [14, 19, 26, 27]. One additional point is added for patients with fewer than 12 years of education. From a total of 30 points, a score of $<26$ has been defined as a score that indicates NPDs [28].

The Rapid Evaluation of Cognitive Function (ERFC = Évaluation Rapide des Fonctions Cognitives [29]) is another screening tool for the evaluation of NPDs in the aSAH population. Although it has been studied less than the other screening tools, its reliability (intra-class correlation coefficient $=$ $0.87, p<0.001)$ and concurrent validity with the MiniMental State Examination (MMSE) test has been demonstrated $(0.91, p<0.001)$ [30]. The test contains 12 items that assess spatial orientation, attention span, immediate and deferred memory, reasoning and judgment, mental calculation, comprehension, repetition, denomination, execution of a written order, apraxia, verbal fluency, visual decoding and writing. From a total of 50 points, a score of $<46$ has been defined as a score that indicates NPDs [31]. The ERFC-based evaluations were performed by fully-trained occupational therapists.

\section{Statistical analyses}

Baseline patient characteristics were summarized using mean values with standard deviation in continuous variables, 
whereas categorical variables were reported using frequencies with proportions as a percentage. The differences between included and excluded patients were evaluated using independent t-tests (continuous variables) and Fisher's exact tests (categorical variables). Descriptive statistics were used to report the proportion of patients categorized with favorable outcome that showed NPDs according to the MoCA or ERFC. In addition, NPDs were investigated separately in groups with good $(\mathrm{mRS}=1)$ and excellent $(\mathrm{mRS}=0)$ outcome. The relationship between the reference variable (mRS) and each of the NPD screening tools (MoCA and ERFC) was calculated with Spearman's correlation coefficients. The strength of the correlation was categorized as weak $(0.10-0.29)$, moderate $(0.30$ $0.49)$ or strong $(0.50-1.00)$ [32]. Linearity was analyzed with a linear regression model (Coefficient and 95\% confidence interval (CI)), while the influence of age and sex were adjusted with multiple linear regression. Relationships are graphically presented by scatter plots with fitted regression lines and $95 \%$ CIs. Analyses were performed with Stata version 14.2 (Stata Corp, College Station, TX). $p$ values $<0.05$ were considered statistically significant.

\section{Results}

Of the 170 aSAH patients, $42(24.7 \%)$ performed at least one out of the two specific NPD tests during hospitalization, and thus were included in our analysis. The specific proportions for the MoCA and ERFC were 18.2\% $(n=31)$ and $9.4 \%(n=$ $16)$, respectively. On average, the patients included in the analysis showed milder aSAHs $(p=0.002)$, hospitalization periods that were six days shorter $(p=0.011)$, and more favorable hospital discharge status $(p=0.024)$ compared to aSAH patients who were evaluated only by the mRS (Table 1). NPD screenings were performed on average sixteen (interquartile range $(\mathrm{IQR})=13-21$ ) days after aSAH whereas median difference to $\mathrm{mRS}$ assessments was two (IQR $=0-5$ ) days. None of the analyzed patients had excellent functional outcome $(\mathrm{mRS}=0)$ at discharge.

\section{MoCA and $m R S$}

Of the 31 patients with MoCA measurements, nine were categorized with good outcome status $(\mathrm{mRS}=1)$ and 26 with favorable outcome status ( $\mathrm{mRS}=0-2)$ at hospital discharge. The prevalence of NPDs was high among these patients: of the nine patients with good outcome and the 26 with favorable outcome, six (66.7\%) and 14 (53.8\%), respectively, had neuropsychological impairments according to the MoCA. The correlation between the MoCA and mRS was nonsignificant (Fig. 1; Table 2).

\section{ERFC and $m R S$}

Of the 16 patients with ERFC measurements, nine were categorized with good outcome status $(\mathrm{mRS}=1)$ and 12 with favorable outcome status $(\mathrm{mRS}=0-2)$ at hospital discharge. In line with the results of the MoCA, seven of the nine patients with good outcome (77.8\%) and eight of the 12 with favorable outcome $(66.7 \%)$ had NPDs according to the ERFC. Similar to the MoCA, there was no correlation between the ERFC and mRS, as hypothesized (Fig. 2; Table 2).

\section{Discussion}

The results of this preliminary and retrospective study suggest that the MoCA and ERFC are valuable instruments for the early detection of NPDs in aSAH patients that are in relatively good condition and might be considered for home discharge instead of inpatient rehabilitation. We found NPDs in more than half of the patients that were categorized with favorable outcome according to the mRS (using the described cut-off values for cognitive impairment). NPDs and mRS scores showed no correlation, suggesting that functional and neuropsychological outcomes should be assessed independently. As discharge status and the perceived disabilities at discharge are key indicators for the choice of proper rehabilitation, the simple outcome screening tools examined here would likely help to recognize those aSAH patients who would benefit from a more detailed neuropsychological workup and early neuropsychological rehabilitation.

The favorable outcome status has generally included mRS categories $0-2$. However, in order to exclude patients with slight disabilities, a more strict definition has been proposed for this status, which only includes mRS categories of 0 and 1 [33]. Our study shows that the mRS is unable to detect neuropsychological impairments, regardless of the cut-off range. In fact, according to the MoCA and ERFC, the proportions of NPDs were even higher (66.7\% and $77.8 \%$, respectively) in aSAH patients with good $\mathrm{mRS}$ outcome $(\mathrm{mRS}=1)$. This finding suggests that even when the function of aSAH patients appears similar to the pre-ictal level, simple but validated neuropsychological screening tools can reveal impairments that might otherwise remain unnoticed. Prior works from Haug Nordenmark et al. [15] elucidated a significant mismatch between an - apparently - favorable outcome on the mRS and severely impaired global cognitive function in the acute phase (close to discharge from the hospital). It is possible that with ongoing recovery over time the cognitive scores and disability grading scales align better, however. At three months after the ictus, Wong et al. [27] demonstrated a moderate negative correlation between the $\mathrm{mRS}$ and Chinese version of the MoCA $(-0.413, p<0.001)$. One drawback of both our current and the previous study from Haug Nordenmark et al. [15] are the 
Table 1 Characteristics of 170 consecutive aneurysmal subarachnoid hemorrhage patients that were discharged after aneurysmal subarachnoid hemorrhage. The table illustrates (by bolded text) that patients included in this study had lighter World Federation of Neurosurgical Societies admission scores and developed hydrocephalus less frequently. Accordingly, their hospitalization was around six days shorter and their discharge status was more favorable

\begin{tabular}{|c|c|c|c|}
\hline & No NPD measurement (excluded) & MoCA and/or ERFC measured (included) & p value \\
\hline Age, mean (SD) & $55.5(12.6)$ & $55.8(11.3)$ & 0.89 \\
\hline Sex, male $(\%)$ & $47(36.7)$ & $12(28.6)$ & 0.36 \\
\hline Hypertension, n (\%) & $42(32.8)$ & $16(38.1)$ & 0.58 \\
\hline Smoker, n (\%) & $40(31.3)$ & $19(45.2)$ & 0.13 \\
\hline $\begin{array}{l}\text { WFNS, n }(\%) \\
\text { I } \\
\text { II } \\
\text { III } \\
\text { IV } \\
\text { V }\end{array}$ & $\begin{array}{l}44(34.4) \\
24(18.8) \\
6(4.7) \\
29(22.7) \\
25(19.5)\end{array}$ & $\begin{array}{l}25(59.5) \\
9(21.4) \\
2(4.8) \\
6(14.3) \\
0(0)\end{array}$ & 0.002 \\
\hline $\begin{array}{l}\text { Treatment, } \mathrm{n}(\%) \\
\text { Microsurgical (clipping) } \\
\text { Endovascular (coiling) }\end{array}$ & $\begin{array}{l}66(51.6) \\
62(48.4)\end{array}$ & $\begin{array}{l}17(40.5) \\
25(59.5)\end{array}$ & 0.22 \\
\hline Cerebral vasospasm, n (\%) & $49(38.3)$ & $20(47.6)$ & 0.37 \\
\hline Delayed cerebral ischemia, $\mathrm{n}(\%)$ & $27(21.1)$ & $10(23.8)$ & 0.83 \\
\hline Hydrocephalus, n (\%) & $84(65.6)$ & $17(40.5)$ & 0.006 \\
\hline $\begin{array}{l}\text { BNI-scale, n }(\%) \\
\text { 1) } \\
\text { 2) } \\
\text { 3) } \\
\text { 4) } \\
\text { 5) }\end{array}$ & $\begin{array}{l}5(3.9) \\
10(7.8) \\
42(32.8) \\
52(40.6) \\
19(14.8)\end{array}$ & $\begin{array}{l}0(0) \\
3(7.1) \\
21(50.0) \\
15(35.7) \\
3(7.1)\end{array}$ & 0.26 \\
\hline Length of hospitalization in days, mean (SD) & $29.1(16.1)$ & $23.6(10.2)$ & 0.011 \\
\hline $\begin{array}{l}\mathrm{mRS} \text { at discharge, } \mathrm{n}(\%) \\
0-2 \text { (favorable outcome) } \\
3-5 \text { (unfavorable outcome) }\end{array}$ & $\begin{array}{l}78(60.9) \\
50(39.1) \\
\boldsymbol{n}=\mathbf{1 2 8}(\mathbf{1 0 0 \%})\end{array}$ & $\begin{array}{l}34(81.0) \\
8(19.0) \\
n=42(100 \%)\end{array}$ & 0.024 \\
\hline
\end{tabular}

$\mathrm{NPD}=$ neuropsychological deficit

$\mathrm{MoCA}=$ Montreal Cognitive assessment

$\mathrm{ERFC}=$ The Rapid Evaluation of Cognitive Function

WFNS $=$ World Federation of Neurosurgical Societies

$\mathrm{BNI}=$ Barrow Neurological Institute

$\mathrm{mRS}=$ modified Rankin Scale

limited sample sizes, which cannot exclude the possibility that the analyses were underpowered to detect a significant correlation. Still, the impressive contrast between relatively mild functional impairment and severely reduced cognitive abilities outlined in both studies leave little room for doubt that the mRS does not qualify to judge upon the need for neuropsychological rehabilitation after hospital discharge.

It has been 25 years since Hütter and Gilsbach highlighted that six months post-aSAH, neuropsychological deficits were frequent even among SAH patients that seemed to fare well. [6] Since then, similar findings have been reported by several other research groups $[11,34,35]$. However, we found only one study that evaluated the incidence of NPDs in patients with favorable functional outcome at the early stages after aSAH. Specifically, Haug Nordenmark et al. [15] reported that $57 \%$ of all discharged aSAH patients had a poor cognitive outcome. Similar to our results, nearly half of the cases were still graded with favorable outcome (mRS $0-2)$. Their conclusion was that in addition to the mRS, another neuropsychological screening tool should be used to identify early NPDs after aSAH. However, the authors did not suggest any specific, short and practical screening tool - which is what we have provided in the present paper.

One of our screening tools, the MoCA, has also been considered by the NIH/NINDS CDE as a first-line neuropsychological screening tool among aSAH patients [22]. The sensitivity for milder NPDs is reportedly high, and the tool has therefore been graded as superior to other commonly used cognitive screening tools, such as MMSE $[19,26]$. In fact, in the recent study of 337 aSAH patients, Eagles et al. [35] concluded that although MMSE scores varied in favorable outcome patients (mRS 0 -2) 12 weeks after aSAH, more sensitive variables, 
Fig. 1 Correlation between the MoCA and $\mathrm{mRS}$

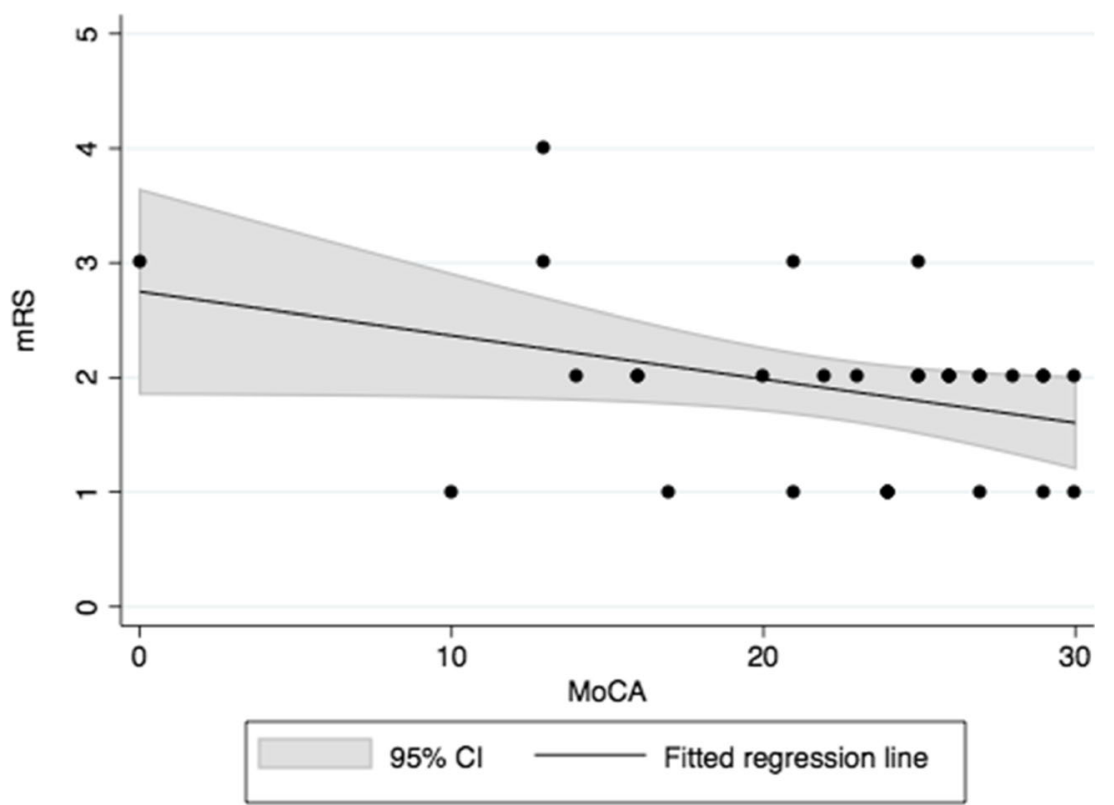

such as the MoCA, should be used to detect milder NPDs among these patients. Similarly, three studies by Wong et al. have investigated the relationship between the $\mathrm{mRS}$ and MoCA $[20,27,36]$. The first study revealed a low association between the MoCA (measured at a subacute phase (2-4 weeks) after aSAH) and unfavorable functional outcome (mRS 3-5) at one year [36]. In the second study, a moderate negative correlation was found between the Chinese version of the MoCA and mRS three months after aSAH [27]. In the third study, only an excellent outcome $(\mathrm{mRS}=0)$ was associated with the MoCA at one year [20]. Similar to our findings, these results emphasize that the MoCA qualifies as a rational tool to screen the neuropsychological function in aSAH patients. Moreover, our ERFC findings are in line with those of the MoCA. However, as the literature behind the ERFC is limited, we believe that more data is needed to confirm its ability to reliably diagnose SAHassociated NPDs.

\section{Implications for clinical practice and research}

After aSAH, NPDs are frequent when routinely screened for, and can encompass executive functions (up to $76 \%$ of aSAH patients), memory (up to 61\%), language (up to $76 \%$ ) and sleeping (up to 45\%) [10]. These impairments have implications for the affected patients' ADLs, ability to work and quality of life [9, 10]. Self-reported impairments may be even more frequent: Passier et al. [37] found that $95 \%$ of aSAH patients reported cognitive or emotional complaints that caused troubles in ADLs three months after the ictus. Intensive and timely rehabilitation can effectively decrease the amount of dependency and mitigate impairments, even among patient with poor grading at admission $[12,13]$. Considering the high prevalence of NPDs as indicated in this study, an appropriate outcome assessment before hospital discharge will likely guide patients to adequate rehabilitation, thereby reducing individual disabilities and positively affecting patients' return to independent ADLs. Additionally, the reduction of disabilities might mitigate the economic burden of aSAHs, for example by helping otherwise healthy, working-age individuals to return to work [38].

Multidimensional outcome assessment appears similarly important for research: it has been suggested that the lack of appropriate outcome measures is one of the reasons for the failure of many aSAH outcome trials [39]. In addition, it is

Table 2 Correlations between neuropsychological test patterns and the mRS. None of the analyzed patients had excellent outcome $(\mathrm{mRS}=0)$ at discharge

\begin{tabular}{|c|c|c|c|c|c|c|}
\hline \multirow[t]{2}{*}{$\begin{array}{l}\text { Neuropsychological } \\
\text { variable }\end{array}$} & \multirow[t]{2}{*}{ Number of cases } & \multicolumn{2}{|c|}{$\begin{array}{l}\text { Correlation coefficients } \\
\text { with mRS }\end{array}$} & \multirow{2}{*}{$\begin{array}{l}\text { Linearity with } \mathrm{mRS} \\
\mathrm{p} \text { value }\end{array}$} & \multicolumn{2}{|c|}{$\begin{array}{l}\text { Prevalence of NPD in patients with good }(\mathrm{mRS}=1) \text { and } \\
\text { favorable }(\mathrm{mRS}=0-2) \text { outcome, } \mathrm{n}(\%)\end{array}$} \\
\hline & & $\rho(95 \% \mathrm{CI})$ & $\mathrm{p}$ value & & mRS 1 & mRS $0-2$ \\
\hline $\mathrm{MoCA}$ & 31 & $-0.24(-0.62-0.14)$ & 0.208 & 0.052 & 6 of $9(66.7)$ & 14 of $26(53.8)$ \\
\hline ERFC & 16 & $0.050(-0.46-0.56)$ & 0.849 & 0.56 & 7 of $9(77.8)$ & 8 of $12(66.7)$ \\
\hline
\end{tabular}


Fig. 2 Correlation between the ERFC and $\mathrm{mRS}$

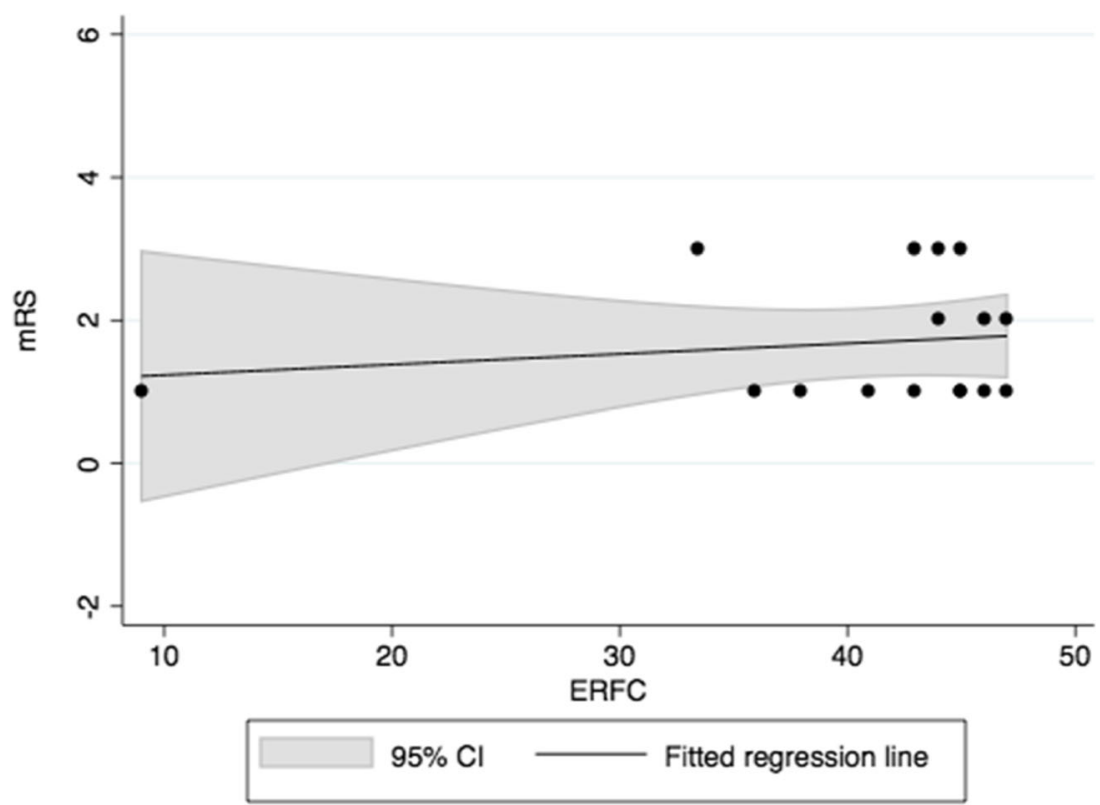

important to implement a more comprehensive and standardized outcome assessment as early as possible in order to identify patients for effective and early rehabilitation after aSAH. Prospective, multi-center research applying the MoCA as a primary endpoint is currently conducted in Switzerland [25]. In addition, multi-national therapeutic trials enrolling aSAH patients apply neuropsychological screening tools as secondary outcomes [40]. Hence, the implication of a neuropsychological outcome assessment provides the potential for many areas to benefit.

The neuropsychological screening tools presented here may even be routinely used by the neurosurgical staff, namely physicians, physician-assistants or nurses that are trained in the application of such tools. The two screening tools examined in our study appear to have a high sensitivity for detecting NPDs, are relatively fast to conduct, and simple enough to use for screening purposes. Given that neuropsychological resources are limited in the majority of neurosurgical departments globally, an approach that screens aSAH patients with favorable outcome before discharge would seem reasonable. Of course, additional workups by professional neuropsychologists should be organized in cases where the neuropsychological screening is abnormal. Overall, we believe that the population of aSAH patients would benefit from such an approach.

\section{Strengths and limitations}

This study provides new data on the association between the $\mathrm{mRS}$, which is currently the "gold standard" in outcome assessment for stroke and $\mathrm{SAH}$, and more in-depth functional and neuropsychological outcome. It confirms previously reported relationships and adds new data to the existing body of literature. In particular, this study does reconfirm previously described relationships in a modern, contemporary series treated according to modern and potentially less traumatizing endovascular and microsurgical techniques. While the MoCA is a relatively well studied and recommended tool for outcome evaluation after aSAH [22], much less experience has been accumulated for the ERFC in this setting. Similar to earlier studies, the conclusions drawn from our analyses are limited by the small sample size and the retrospective nature of the study. This - and the fact that both the MoCA and ERFC are merely screening tools - is why we desisted from more detailed, domain-specific analysis of NPD, as was done in other studies [15] before for the acute setting. In addition, since all our consecutively admitted 170 aSAH patients were not assessed routinely by NPD screening tools, suspicion of NPDs may have had an effect on the patient selection for additional MoCA or ERFC screening. Nevertheless, the consistency between our results and those from prior studies strengthens our confidence in the findings reported here.

\section{Conclusion}

Neuropsychological impairments were frequently identified among aSAH patients that were categorized with favorable outcome according to the mRS. The current work highlights this previously described phenomenon in a contemporary series of aSAH patients managed according to modern guidelines. Moreover, the data show that by employing a reasonably short and inexpensive neuropsychological screening tool, a substantial proportion of patients is identified who might 
benefit from early neuropsychological rehabilitation, even though they appear to fare well. Further studies are necessary to evaluate the actual long-term benefit of such an early screening for the patient.

Acknowledgements Open access funding provided by University of Helsinki including Helsinki University Hospital. We would like to thank Jacquelin DeFaveri for language revision.

Study funding IR would like to thank the Helsinki University Foundation for the research grant. The foundation has no personal or institutional financial interests concerning this study.

\section{Compliance with ethical standards}

Conflict of interest The authors declare that they have no conflict of interest.

Ethical standards.

All procedures performed in studies involving human participants were in accordance with the ethical standards of the local research committee (Kantonale Ethikkommission KEK-ZH 2012-0244) and with the 1964 Helsinki declaration and its later amendments or comparable ethical standards. The patient's informed consent was waived. The study follows the STROBE (Strengthening the Reporting of Observational Studies in Epidemiology) recommendation for observational studies.

Data availability statement.

The datasets generated during and/or analyzed during the current study are available from the corresponding author on reasonable request.

Open Access This article is distributed under the terms of the Creative Commons Attribution 4.0 International License (http:// creativecommons.org/licenses/by/4.0/), which permits unrestricted use, distribution, and reproduction in any medium, provided you give appropriate credit to the original author(s) and the source, provide a link to the Creative Commons license, and indicate if changes were made.

\section{References}

1. Korja M, Silventoinen K, Laatikainen T, Jousilahti P, Salomaa V, Kaprio J (2013) Cause-specific mortality of 1-year survivors of subarachnoid hemorrhage. Neurology 80(5):481-486. https://doi. org/10.1212/WNL.0b013e31827f0fb5

2. Lovelock CE, Rinkel GJ, Rothwell PM (2010) Time trends in outcome of subarachnoid hemorrhage: population-based study and systematic review. Neurology 74(19):1494-1501. https://doi.org/ 10.1212/WNL.0b013e3181dd42b3

3. Stienen MN, Weisshaupt R, Fandino J, Fung C, Keller E, Hildebrandt G, Studerus-Germann A, Muri R, Gutbrod K, Blasi $\mathrm{S}$, Monsch AU, Brugger P, Mondadori C, Sailer M, Bijlenga P, Schaller K, Schatlo B, Swiss SOSsg (2013) Current practice in neuropsychological outcome reporting after aneurysmal subarachnoid haemorrhage. Acta Neurochir 155 (11):2045-2051. doi: https://doi.org/10.1007/s00701-013-1823-9

4. Saver JL, Filip B, Hamilton S, Yanes A, Craig S, Cho M, Conwit R, Starkman S, Investigators F-M, Coordinators (2010) Improving the reliability of stroke disability grading in clinical trials and clinical practice: the Rankin focused assessment (RFA). Stroke 41 (5):992-995. doi:https://doi.org/10. 1161/STROKEAHA.109.571364
5. Jennett B, Bond M (1975) Assessment of outcome after severe brain damage. Lancet 1(7905):480-484

6. Hutter BO, Gilsbach JM (1993) Which neuropsychological deficits are hidden behind a good outcome (Glasgow = I) after aneurysmal subarachnoid hemorrhage? (0148-396X (print))

7. Fung C, Beck J, Lauber L, Muri R, Raabe A, Nyffeler T (2012) Clinical assessment of deficits after SAH: hasty neurosurgeons and accurate neurologists. J Neurol 259(10):2198-2201. https://doi.org/ 10.1007/s00415-012-6483-9

8. Stienen Martin N, Smoll Nicolas R, Fung C, Goldberg J, Bervini D, Maduri R, Chiappini A, Robert T, May A, Bijlenga P, Zumofen D, Roethlisberger M, Seule Martin A, Marbacher S, Fandino J, Schatlo B, Schaller K, Keller E, Bozinov O, Regli L, null n, Burkhardt J-K, Neidert Marian C, Maldaner N, Finkenstädt S, Schöni D, Raabe A, Beck J, Mariani L, Guzman R, D'Alonzo D, Daniel Roy T, Reinert M, Ferrari A, Hildebrandt G, Weyerbrock A, Corniola M (2018) Home-time as a surrogate marker for functional outcome after aneurysmal subarachnoid hemorrhage. Stroke 49 (12):3081-3084. doi:https://doi.org/10.1161/STROKEAHA.118.022808

9. Rinkel GJ, Algra A (2011) Long-term outcomes of patients with aneurysmal subarachnoid haemorrhage. Lancet Neurol 10(4):349 356. https://doi.org/10.1016/S1474-4422(11)70017-5

10. Al-Khindi T, Macdonald RL, Schweizer TA (2010) Cognitive and functional outcome after aneurysmal subarachnoid hemorrhage. Stroke 41(8):e519-e536. https://doi.org/10.1161/STROKEAHA. 110.581975

11. Ravnik J, Starovasnik B, Sesok S, Pirtosek Z, Svigelj V, Bunc G, Bosnjak R (2006) Long-term cognitive deficits in patients with good outcomes after aneurysmal subarachnoid hemorrhage from anterior communicating artery. Croat Med J 47(2):253-263

12. Haug T, Sorteberg A, Finset A, Lindegaard KF, Lundar T, Sorteberg W (2010) Cognitive functioning and health-related quality of life 1 year after aneurysmal subarachnoid hemorrhage in preoperative comatose patients (Hunt and Hess grade V patients). Neurosurgery 66(3):475-484; discussion 484-475. https://doi.org/ 10.1227/01.NEU.0000365364.87303.AC

13. Greebe P, Rinkel GJ, Algra A (2010) Long-term outcome of patients discharged to a nursing home after aneurysmal subarachnoid hemorrhage. Arch Phys Med Rehabil 91(2):247-251. https://doi. org/10.1016/j.apmr.2009.10.008

14. Zweifel-Zehnder AE, Stienen MN, Chicherio C, StuderusGermann A, Blasi S, Rossi S, Gutbrod K, Schmid N, Beaud V, Mondadori C, Brugger P, Sacco L, Muri R, Hildebrandt G, Fournier JY, Keller E, Regli L, Fandino J, Mariani L, Raabe A, Daniel RT, Reinert M, Robert T, Schatlo B, Bijlenga P, Schaller K, Monsch AU, Swiss SOSsg (2015) Call for uniform neuropsychological assessment after aneurysmal subarachnoid hemorrhage: Swiss recommendations. Acta Neurochir 157 (9):1449-1458. doi: https://doi.org/10.1007/s00701-015-2480-y

15. Haug Nordenmark T, Karic T, Sorteberg W, Sorteberg A (2019) Predictors of cognitive function in the acute phase after aneurysmal subarachnoid hemorrhage. Acta Neurochir 161(1):177-184. https:// doi.org/10.1007/s00701-018-3760-0

16. Sarnthein J, Stieglitz L, Clavien PA, Regli L (2016) A patient registry to improve patient safety: recording general neurosurgery complications. PLoS One 11(9):e0163154. https://doi.org/10. 1371/journal.pone. 0163154

17. Teasdale GM, Drake CG, Hunt W, Kassell N, Sano K, Pertuiset B, De Villiers JC (1988) A universal subarachnoid hemorrhage scale: report of a committee of the world federation of neurosurgical societies. J Neurol Neurosurg Psychiatry 51(11):1457. https://doi.org/ 10.1136/jnnp.51.11.1457

18. Neidert MC, Maldaner N, Stienen MN, Roethlisberger M, Zumofen DW, D'Alonzo D, Marbacher S, Maduri R, Hostettler IC, Schatlo B, Schneider MM, Seule MA, Schoni D, Goldberg J, Fung C, Arrighi M, Valsecchi D, Bijlenga P, Schaller K, Bozinov O, Regli L, 
Burkhardt JK, Swiss SOSsg (2018) The Barrow neurological institute grading scale as a predictor for delayed cerebral ischemia and outcome after aneurysmal subarachnoid hemorrhage: data from a Nationwide patient registry (Swiss SOS). Neurosurgery 83 (6): 1286-1293. doi:https://doi.org/10.1093/neuros/nyx609

19. Wong GK, Lam SW, Wong A, Ngai K, Poon WS, Mok V (2013) Comparison of Montreal cognitive assessment and mini-mental state examination in evaluating cognitive domain deficit following aneurysmal subarachnoid haemorrhage. PLoS One 8(4):e59946. https://doi.org/10.1371/journal.pone.0059946

20. Wong GK, Lam SW, Wong A, Lai M, Siu D, Poon WS, Mok V (2014) MoCA-assessed cognitive function and excellent outcome after aneurysmal subarachnoid hemorrhage at 1 year. Eur J Neurol 21(5):725-730. https://doi.org/10.1111/ene.12363

21. Lees KR, Bath PM, Schellinger PD, Kerr DM, Fulton R, Hacke W, Matchar D, Sehra R, Toni D, European Stroke Organization Outcomes Working G (2012) Contemporary outcome measures in acute stroke research: choice of primary outcome measure. Stroke 43(4):1163-1170. https://doi.org/10.1161/STROKEAHA.111. 641423

22. Stienen MN, Visser-Meily JM, Schweizer TA, Hanggi D, Macdonald RL, Vergouwen MDI, Unruptured Intracranial A, Investigators SCP (2019) Prioritization and timing of outcomes and endpoints after aneurysmal subarachnoid hemorrhage in clinical trials and observational studies: proposal of a multidisciplinary research group. Neurocrit Care 30(Suppl 1):102-113. https://doi. org/10.1007/s12028-019-00737-0

23. Data Coordination Unit at Medical University of South Carolina WebDCU ${ }^{\mathrm{TM}}$ Comprehensive Clinical Trial Management System (https://webdcu.musc.edu/campus/). (2004)

24. Molyneux AJ, Kerr RS, Yu LM, Clarke M, Sneade M, Yarnold JA, Sandercock P, International Subarachnoid Aneurysm Trial Collaborative G (2005) International subarachnoid aneurysm trial (ISAT) of neurosurgical clipping versus endovascular coiling in 2143 patients with ruptured intracranial aneurysms: a randomised comparison of effects on survival, dependency, seizures, rebleeding, subgroups, and aneurysm occlusion. Lancet 366(9488):809-817. https://doi.org/10.1016/S0140-6736(05) 67214-5

25. Stienen MN, Fung C, Bijlenga P, Zumofen DW, Maduri R, Robert T, Seule MA, Marbacher S, Geisseler O, Brugger P, Gutbrod K, Chicherio C, Monsch AU, Beaud V, Rossi S, Fruh S, Schmid N, Smoll NR, Keller E, Regli L, Mo CADCIsg (2018) Measuring the impact of delayed cerebral ischemia on neuropsychological outcome after aneurysmal subarachnoid hemorrhage-protocol of a Swiss Nationwide observational study (MoCA-DCI study). Neurosurgery. doi:https://doi.org/10.1093/neuros/nyy155

26. Schweizer TA, Al-Khindi T, Macdonald RL (2012) Mini-mental state examination versus Montreal cognitive assessment: rapid assessment tools for cognitive and functional outcome after aneurysmal subarachnoid hemorrhage. J Neurol Sci 316(1-2):137-140. https://doi.org/10.1016/j.jns.2012.01.003

27. Wong GK, Lam S, Ngai K, Wong A, Mok V, Poon WS, Cognitive Dysfunction after Aneurysmal Subarachnoid Haemorrhage I (2012) Evaluation of cognitive impairment by the Montreal cognitive assessment in patients with aneurysmal subarachnoid haemorrhage: prevalence, risk factors and correlations with 3 month outcomes. J Neurol Neurosurg Psychiatry 83 (11):1112-1117. doi:https://doi. org/10.1136/jnnp-2012-302217

28. Nasreddine ZS, Phillips NA, Bedirian V, Charbonneau S, Whitehead V, Collin I, Cummings JL, Chertkow H (2005) The
Montreal cognitive assessment, MoCA: a brief screening tool for mild cognitive impairment. J Am Geriatr Soc 53(4):695-699. https://doi.org/10.1111/j.1532-5415.2005.53221.x

29. Gil RT, G, Pluchon C, Micheneau D, Cariou B, Rivault L, Sicot I, Boissonnot L, Neau JP. (1987) A method for rapid evaluation of cognitive faculties (ERFC) - use in Alzheimer senile dementia. Semanie des Hopitaux 67:2127-2133

30. Billon R (1991) Une méthode d'évaluation rapide des fonctions cognitives et une épreuve raccourcie. Revue de Gériatrie 16(5): 229-234

31. Kemoun G, Thibaud M, Roumagne N, Carette P, Albinet C, Toussaint L, Paccalin M, Dugue B (2010) Effects of a physical training programme on cognitive function and walking efficiency in elderly persons with dementia. Dement Geriatr Cogn Disord 29(2):109-114. https://doi.org/10.1159/000272435

32. Cohen J (1988) Statistical power analysis for the behavioral sciences, 2nd edn. Lawrence Erlbaum, New Jersey

33. Weisscher N, Vermeulen M, Roos YB, Haan RJ (2008) What should be defined as good outcome in stroke trials; a modified Rankin score of $0-1$ or $0-2$ ? J Neurol 255(6):867-874. https:// doi.org/10.1007/s00415-008-0796-8

34. Kim DH, Haney CL, Van Ginhoven G (2005) Utility of outcome measures after treatment for intracranial aneurysms: a prospective trial involving 520 patients. Stroke 36(4):792-796. https://doi.org/ 10.1161/01.STR.0000157594.58180.97

35. Eagles ME, Tso MK, Macdonald RL (2019) Cognitive impairment, functional outcome, and delayed cerebral ischemia after aneurysmal subarachnoid hemorrhage. World Neurosurg. https://doi.org/ 10.1016/j.wneu.2018.12.152

36. Wong GK, Lam SW, Wong A, Mok V, Siu D, Ngai K, Poon WS (2014) Early MoCA-assessed cognitive impairment after aneurysmal subarachnoid hemorrhage and relationship to 1-year functional outcome. Transl Stroke Res 5(2):286-291. https://doi.org/10.1007/ s12975-013-0284-Z

37. Passier PE, Visser-Meily JM, van Zandvoort MJ, Post MW, Rinkel GJ, van Heugten C (2010) Prevalence and determinants of cognitive complaints after aneurysmal subarachnoid hemorrhage. Cerebrovasc Dis 29(6):557-563. https://doi.org/10.1159/ 000306642

38. Rivero-Arias O, Gray A, Wolstenholme J (2010) Burden of disease and costs of aneurysmal subarachnoid haemorrhage (aSAH) in the United Kingdom. Cost Eff Resour Alloc 8:6. https://doi.org/10. 1186/1478-7547-8-6

39. Macdonald RL, Cusimano MD, Etminan N, Hanggi D, Hasan D, Ilodigwe D, Jaja B, Lantigua H, Le Roux P, Lo B, Louffat-Olivares A, Mayer S, Molyneux A, Quinn A, Schweizer TA, Schenk T, Spears J, Todd M, Torner J, Vergouwen MD, Wong GK, Collaboration S (2013) Subarachnoid hemorrhage international Trialists data repository (SAHIT). World Neurosurg 79(3-4):418 422. https://doi.org/10.1016/j.wneu.2013.01.006

40. Idorsia Pharmaceuticals Ltd Clinical Research Study With Clazosentan to Evaluate Its Effects on Preventing Complications Due to the Narrowing of the Blood Vessels (Vasospasm) in the Brain, Caused by Bleeding Onto the Surface of the Brain, Identifier NCT03585270 ClinicalTrials.gov (2018)

Publisher's note Springer Nature remains neutral with regard to jurisdictional claims in published maps and institutional affiliations. 